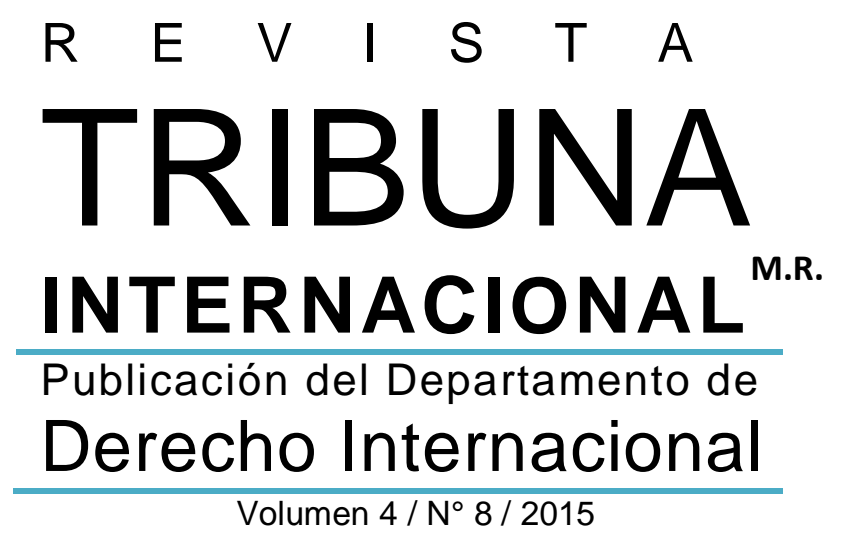

FACULTAD DE DERECHO 


\section{Rector de la Universidad de Chile}

Ennio Vivaldi Véjar

Av. Alameda Libertador Bernardo O'Higgins 1058, Santiago

\section{Representante legal}

Davor Harasic Yaksic

Decano de la Facultad de Derecho

Universidad de Chile

\section{Director Departamento Derecho Internacional}

Edmundo Vargas Carreño

\section{Director (S) Revista Tribuna Internacional}

Mario Arnello Romo

\section{Editor General Revista Tribuna Internacional}

Luis Valentín Ferrada Walker

\section{Comité Editorial}

Íñigo Álvarez Gálvez (Universidad de Chile, Chile)

Gonzalo Aguilar (Universidad de Talca, Chile)

José Carlos Fernández Rosas (Universidad

Complutense de Madrid, España)

Claudio Grossman (American University, EE.UU.)

Mattias Kumm (New York University, EE.UU.)

Hugo Llanos (Universidad Central, Chile)

Cecilia Medina (Universidad Diego Portales, Chile)

Elina Mereminskaya (Universidad de Chile, Chile)

Mónica Pinto (Universidad de Buenos Aires, Argentina)

\section{Fundador de la Revista Tribuna Internacional}

Mario Ramírez Necochea $†$

\section{Revista Tribuna Internacional M.R.}

Publicación del Departamento de Derecho Internacional de la Facultad de Derecho de la Universidad de Chile. Su objetivo es fomentar la reflexión, el debate, el análisis y la comunicación sobre el derecho internacional en forma pluralista y con rigor científico. Se publica cada semestre en los meses de junio y diciembre mediante convocatoria abierta a la publicación de artículos y monografías inéditos, comentarios de jurisprudencia, recensiones y comentarios de libros, en los campos de derecho internacional público y privado, derecho internacional de los derechos humanos y relaciones internacionales, tanto en castellano como inglés.

La Revista Tribuna Internacional fue creada por Decreto Exento No 8.466 de la Rectoría de la Universidad de Chile, de 22 de marzo del 2011

Volumen 4/ No 8 / 2015

www.tribunainternacional.uchile.cl ISSN 0719-482X (versión en línea)

Departamento de Derecho Internacional Facultad de Derecho Universidad de Chile Av. Santa María 076, $4^{\circ}$ piso Providencia, Santiago de Chile

\section{Diseño y producción:}

Facultad de Derecho

Universidad de Chile

Se autoriza la reproducción total o parcial del contenido de la publicación, siempre que se reconozca y cite el/ la/ los/ las autor/a/es/as y la publicación, no se realicen modificaciones a la obra y no se la utilice para fines comerciales. 


\title{
La justiciabilidad de la reforma constitucional en la República Argentina. El caso Fayt ${ }^{1}$
}

\author{
The Justiciability of the Constitutional Reform in Argentina. The "Fayt" Case
}

\author{
Alvaro Fuentealba Hernández \\ afuentealba@derecho.uchile.cl \\ Profesor Asociado del Departamento de Ciencias del Derecho, Facultad de Derecho de la Universidad \\ de Chile.
}

Resumen: A propósito del llamado "caso Fayt", el artículo presenta un análisis teórico de los alcances del poder constituyente derivado en el derecho comparado latinoamericano, y las elaboraciones de la doctrina constitucional europea. Asimismo, se analiza la forma cómo el derecho constitucional argentino ha abordado estas materias, de total actualidad en Chile. Se aborda el problema de los límites a la potestad constituyente y si éstos son susceptibles de conocimiento por la justicia constitucional.

Palabras Clave: Justiciabilidad - reforma constitucional - poder constituyente - Convención Nacional Constituyente argentina.

Abstract: In connection with the "Faye" case law, the paper makes a theoretical analysis about the extention of the derived constitutional power on the Latin American Comparative Law and the elaborations of the European constitutional doctrine. Also, the autor analyses how the Argentinian constitutional law has treated this matters, which is as much important as in Chile. The article approaches to the issue of the limits to the constitutional power and if them can be judged by the Constitutional Justice.

Keywords: Justiciability - Constitutional Reform - Constitutional Power - Argentinian National Constitutional Convention.

Comentario jurisprudencial enviado el 20.08.2015 y aceptado el 13.12.2015. 


\section{Introducción}

La estabilidad del orden constitucional es una aspiración legítima de todo sistema político. No obstante ello, y justamente con la finalidad de mantener la estabilidad de la comunidad que le da sustento a dicho sistema político, la gran mayoría de los órdenes constitucionales del mundo establecen normas que regulan la modificación de los textos constitucionales.

En palabras de Häberle ${ }^{2}$, debemos distinguir la situación que se da entre el proceso constituyente y la reforma constitucional, es decir, si el mecanismo autoriza o no la enmienda total de la Constitución, y si existen o no cláusulas intangibles. Y en cuanto a la reforma constitucional, la pregunta básica, entonces, está referida a los límites al ejercicio del poder constituyente derivado, por una parte, y por otra, a los mecanismos de control de la extralimitación, y el alcance de las subsecuentes potestades normativas públicas que el órgano de control posea ${ }^{3}$.

El citado autor señala que "la modificación constitucional es el procedimiento institucionalizado de adaptación de la Constitución al cambio cultural y para la iniciación activa de medidas para dicho cambio" 4 .

Contrariamente a lo que se pueda pensar, estas definiciones no son simples, ni aún en los órdenes constitucionales que, como el argentino, parecieran tener resueltos estos temas por la explícita regulación constitucional del procedimiento y los órganos de la reforma constitucional, por una parte, y por otra, el ámbito de competencias de los órganos de control de la constitucionalidad ${ }^{5}$.

El caso Fayt $^{6}$ puede ser calificado como señero en estas definiciones, ya que la doctrina establecida en el mismo no tiene precedentes en el derecho constitucional argentino ${ }^{7}$. Se erige también en un caso de estudio para su eventual comparación con otros ordenamientos constitucionales. Es relevante, en este sentido, para países como Chile, actualmente inmerso en

HÄBERle, Peter. El Estado Constitucional. Buenos Aires, Astrea, 2007, pp. 240-263.

Interesante debate es el que se puede dar acerca de los alcances de abrogación de una reforma constitucional por parte de un órgano contra mayoritario, como un tribunal, en desmedro de una Convención o Asamblea Constituyente, generada por un proceso democrático mayoritario.

4 HäBERLE, El Estado Constitucional..., op.cit., p. 253.

5 En Chile, por ejemplo, la inconstitucionalidad de una reforma a la Constitución sólo puede plantearse a través de una "cuestión de constitucionalidad" que se haya presentado por diputados o senadores, ante el Tribunal Constitucional, durante la tramitación de una ley de reforma a la Constitución. Una vez promulgada la reforma, precluye la oportunidad de impugnación, careciendo cualquier tribunal de competencias para cuestionarla (artículo 93, $\mathrm{N}^{\circ} 3^{\circ}$ de la Constitución Política de la República de Chile).

6 El caso fue resuelto por la Sala III de la Cámara Nacional de Apelaciones en lo Contencioso Administrativo Federal el 19 de noviembre de 1998, y posteriormente conocido por la Corte Suprema de la Nación (caso F100XXXV, caratulado como 2000-C, 543 Fayt, Carlos S. c. Estado Nacional) la que falló el 19 de agosto de 1999.

7 Ferreyra, Raúl Gustavo. Reforma Constitucional y Control de Constitucionalidad. Limites a la Judiciabilidad de la Enmienda. Buenos Aires, EDIAR, 2007, pp. 211-226. 
Revista Tribuna Internacional

Volumen $4 \cdot \mathrm{N}^{\text {o }} 8 \cdot 2015 \cdot$ pp. $255-269$

ISSN 0719-482X (versión en línea)

una discusión de modificación constitucional. Las normas y órganos que a continuación se citan, y salvo indicación expresa en contrario, son los propios de las República Argentina.

\section{Los hechos}

\subsection{Breve presentación del caso}

Un ministro de la Corte Suprema de Justicia de la Nación, Carlos Santiago Fayt, promovió acción meramente declarativa de certeza tendiente a obtener la invalidación de la modificación introducida por la Convención Nacional Constituyente de 1994 al artículo 99, inciso $4^{\circ}$ de la Constitución Nacional, en cuanto a la garantía de inamovilidad de los jueces (artículo 110 de la Carta Política, que establece que los magistrados conservarán sus empleos "mientras dure su buena conducta", sin agregar modalidad adicional alguna). El juez nació el 1 de febrero de 1918 y fue nombrado por el Presidente Alfonsín en 1983 para servir el cargo de juez de la Corte Suprema de Justicia de la Nación. La innovación de la modificación consistía en que, una vez que los jueces cumpliesen 75 años de edad, necesitarían de un nuevo nombramiento para mantenerse en funciones, el que se haría sólo por cinco años más, pudiendo renovarse indefinidamente. Existía, entonces, la posibilidad de que el Presidente y el Senado no renovasen el nombramiento del juez, lo que en opinión del Fayt atentaba contra la inamovilidad.

En subsidio, el juez pidió que se declarase que tal precepto y la cláusula undécima transitoria no lo afecta por haberse efectuado su designación bajo el régimen constitucional anterior, produciéndose a su respecto una ultra-actividad del texto constitucional derogado. La Cámara de Apelaciones de lo Contencioso Administrativo, modificando el pronunciamiento de primera instancia, formuló esta última declaración. El Procurador General de la Nación dedujo recurso extraordinario en representación del Estado Nacional. Conociendo del recurso, la Corte Suprema de Justicia de la Nación revocó la decisión de cámara, hizo lugar a la demanda y declaró la nulidad de la cláusula constitucional impugnada.

\subsection{Argumentos del Procurador General de la Nación}

En el recurso extraordinario, el Procurador General de la Nación presentó los siguientes argumentos:

a) No existe una división entre los magistrados federales designados bajo el régimen previsto por la Constitución, en su texto anterior a la reforma de 1994, y los magistrados nombrados por el nuevo régimen; no existen, en consecuencia, derechos adquiridos frente a la 
modificación de la norma que otorgaba la inamovilidad pura y simple y no condicionada en el ejercicio del cargo que, por ende, podía (y puede) ser vitalicio;

b) No hay modificación a la garantía de la inamovilidad de los jueces, pues el artículo 99 inciso $4^{\circ}$ de la Constitución Nacional contiene una exigencia de carácter objetivo e impersonal (la edad del magistrado, que gatilla un procedimiento especial de ratificación o revocación del cargo);

c) La reforma constitucional en el punto que se halla en discusión es válida y responde a los términos de la norma que la convocó y que le atribuyó competencia; ello es así, pues tanto el artículo $2^{\circ}$ de la Ley $N^{\circ} 24.309$ (1993), como el "Núcleo de Coincidencias Básicas", contemplaron como materia de revisión lo relativo a la "designación de los jueces federales";

d) La sentencia está viciada por incongruencia, por no aplicar una norma constitucional sin pronunciarse sobre su validez; $y$,

e) También incurre en arbitrariedad por no rebatir los fundados argumentos de su parte, contrarios a la admisibilidad de la acción declarativa en el caso sub lite.

\subsection{Pretensiones y argumentos del Juez Fayt}

El 11 de julio de 1997, el juez Fayt inició una acción (artículo 322 del Código Procesal Civil y Comercial de la Nación), para obtener la declaración de nulidad, en los términos de la Ley $\mathrm{N}^{\circ}$ 24.309, de la reforma introducida por el artículo 99, inciso $4^{\circ}$, párrafo tercero, del nuevo texto de la Constitución, al artículo 86, inciso $5^{\circ}$ del texto anterior.

Es del caso hacer notar que la Ley $\mathrm{N}^{\circ} 24.309$ establecía la sanción de nulidad de cualquier innovación incorporada fuera del ámbito de materias que la referida ley, que declaró la necesidad de la reforma.

Se invocó al respecto la afectación del derecho a la inamovilidad de los magistrados mientras mantengan su buena conducta, consagrado en el actual artículo 110 de la Carta Magna (anterior artículo 96), en cuanto establece que un nuevo nombramiento, precedido de acuerdo del Senado $^{8}$, es necesario para mantener en el cargo a cualquier magistrado, una vez que cumpla 75 años de edad. Asimismo, arguyó que tal enmienda importaba dicha restricción en circunstancias que no es una enmienda habilitada por la Ley $\mathrm{N}^{\circ} 24.309$, que declara la necesidad de reforma, ya que no habilita a la Convención Nacional Constituyente para poder reformar el instituto de la inamovilidad de los magistrados. En efecto, dicha modificación se introduce al instituto de las potestades Presidenciales, y no a propósito de la regulación del Poder Judicial.

8 Que exige el acuerdo de las dos terceras partes de los miembros de la Cámara. 
Revista Tribuna Internacional

Volumen $4 \cdot \mathrm{N}^{\text {o }} 8 \cdot 2015 \cdot$ pp. $255-269$

ISSN 0719-482X (versión en línea)

El actor, en consecuencia, invocó ante el Poder Judicial la protección de un derecho: el de mantener la inamovilidad en el cargo de juez del tribunal para el cual fue designado según el procedimiento vigente para entonces en la Constitución Nacional y de acuerdo al alcance que dicha garantía le reconocía.

\section{Problemática jurídica del caso}

\subsection{Límites al Poder Constituyente Derivado}

En primer lugar, debemos señalar que el control de constitucionalidad es un derecho de los ciudadanos en contra de normas y actuaciones inconstitucionales ${ }^{9}$. La pregunta relevante acá, sin embargo, es acerca de la judiciabilidad de la enmienda constitucional. Sobre este particular, comúnmente se distingue entre cuestiones políticas no justiciables y causas constitucionales ${ }^{10}$. Bidart Campos señala en este punto que la clave de diferenciación es el conflicto de intereses de relevancia jurídica, es decir, siempre que estemos ante una "causa", es decir, una situación reclamada en que alguien invoca un derecho afectado, estamos en presencia de una causa constitucional, y por ende, justiciable ${ }^{11}$.

Nogueira señala sobre este particular que la distinción entre poder constituyente originario y derivado es nítida, y por ende, "una vez terminada dicha obra cuyo producto es la Constitución, el poder constituyente cesa y surgen los poderes constituidos que sustentan su actuación en su previsión constitucional. Surge, así, la separación nítida entre poder constituyente y poderes constituidos o instituidos por la Constitución y subordinados a la misma"12. A partir de esta última afirmación, podemos concluir que la subordinación del poder constituyente derivado a la Constitución, implica asimismo, de existir en ese determinado régimen constitucional un sistema de judicial review, la sumisión de la reforma a la competencia de los tribunales, para su examen de constitucionalidad. Aunque parezca paradojal, el poder "constituyente" derivado se ejerce a partir del poder "constituido". En efecto, es un poder constituido" ${ }^{13}$.

La teoría constitucional señala que una característica básica del poder constituyente derivado es que no puede "destruir" la Carta Fundamental, por tanto está expresa o implícitamente limitado y subordinado a la Constitución vigente, cuya modificación va a sancionar. Otra

\footnotetext{
Bidart Campos, Germán. Manual de la Constitución Reformada. $4^{a}$ edición. Buenos Aires, Ediar, 2006, tomo I, p. 86.

10 Sobre esta cuestión, es interesante la jurisprudencia de la Corte Suprema Federal Americana, p. e. en "Luther v. Borden", "White v. Hart" (Citada en FERREYRA, Reforma Constitucional..., op.cit., pp. 253-258).

11 BidART CAmpos, Manual de la Constitución..., op.cit., p. 84.

12 Nogueira, Humberto. "Consideraciones sobre Poder Constituyente y Reforma de la Constitución en la Teoría y la Práctica Constitucional”, en Revista Ius et Praxis, v. 15. N 1. Talca, Universidad de Talca, 2009, p. 231.

13 Nogueira, “Consideraciones sobre Poder Constituyente...", op.cit., p. 239.
} 
problemática que puede surgir de esta idea es preguntarnos por la naturaleza del poder constituyente cuando la propia Constitución autoriza su modificación total, como el caso argentino. ¿Estaría en ese caso ejerciéndose el poder constituyente derivado? No obstante ello, en el caso en análisis no podría plantearse dicha cuestión, ya que la Convención Nacional Constituyente de 1994 actuó -o debía actuar- dentro de los precisos límites que le impuso la Ley $\mathrm{N}^{\circ}$ 24.309, declaratoria de la necesidad de reforma. Tanto es así, que se estableció la sanción de nulidad que dio pie a la sentencia que analizamos.

En efecto, el fallo señala, para zanjar esta discusión, que "el Congreso -al declarar la necesidad de reforma constitucional y fijar los límites de la convención reformadora mediante una ley-, ha aceptado el carácter justiciable de los límites del poder reformador, al prever la sanción de nulidad de 'las modificaciones, derogaciones y agregados' que realice aquélla apartándose de la competencia establecida (artículo $6^{\circ}$, ley 24.309 -Adla, LIV-A, 89-), con lo que presupone la existencia de un poder dotado de facultades suficientes para realizar el control sobre el alcance de las disposiciones y derogaciones adoptadas".

El argumento de la Corte Suprema Argentina precisa que la Convención Constituyente se reunió con la finalidad de modificar aquellas cláusulas constitucionales que el Congreso declaró que podían ser reformadas y sobre las que el pueblo tuvo oportunidad de pronunciarse al elegir a los convencionales y no otras, sobre las que no concurren dichos requisitos. La determinación jurídica básica en este punto estriba, entonces, en si se extralimita o no la Convención cuando establece modalidades a la inamovilidad de los magistrados so pretexto de regular las potestades presidenciales. La Corte estima que no podría razonablemente aceptarse aquello ${ }^{14}$.

La pregunta que se hace la Corte es, entonces, si el artículo 96 consagrado en la Constitución de 1853 (actual 110) que disponía que los jueces de la Corte Suprema y de los tribunales inferiores de la Nación mantienen sus empleos mientras dure su buena conducta, fue incluido o no entre las cláusulas que la Convención reformadora estaba habilitada para revisar, según los artículos $2^{\circ}$ y $3^{\circ}$ de la Ley $N^{\circ} 24.309$ (Adla, LIV-A, 89). La conclusión es negativa. Ese precepto no se incluyó en el catálogo de reformas que el Congreso autorizó a incluir a la Convención Nacional Constituyente.

A mayor abundamiento, la Corte examina el Núcleo de Coincidencias Básicas, Pacto de Olivos o Pacto de La Rosada. Concluye que "en ningún párrafo de los puntos I y J del Núcleo de Coincidencias Básicas para la reforma constitucional de 1994, relativos a la designación y a la remoción de los magistrados federales -temas que correspondían a las reformas de los arts. 86, inc. $5^{\circ}$ y 45 de la Constitución Nacional-, aparece algún contenido que pudiera interpretarse

14 Sobre el punto, la sentencia señala: "No puede admitirse que, con motivo de la reforma de una cláusula relativa a las atribuciones del Poder Ejecutivo nacional -intervención del Presidente de la Nación en la designación de los magistrados federales- art. 99, inc. $4^{\circ}$ de la Constitución reformada -materia explícitamente habilitada en el art. $2^{\circ}$ inc. a, de la ley 24.309 (Adla, LIV-A, 89) -, la convención reformadora incorpore una cláusula extraña a las atribuciones de aquel Poder, como es la inamovilidad de los magistrados". 
Revista Tribuna Internacional

Volumen $4 \cdot \mathrm{N}^{\text {o }} 8 \cdot 2015 \cdot$ pp. $255-269$

ISSN 0719-482X (versión en línea)

racionalmente como relativo a la posibilidad de fijar un término a la garantía de inamovilidad de aquéllos con motivo del cumplimiento de una edad determinada".

El voto del juez Vásquez es muy enfático en este orden de ideas: “14. Que, a esta altura, es menester poner de relieve que, de ningún modo, los poderes conferidos a una Convención Constituyente pueden reputarse ilimitados, porque el ámbito de aquellos se halla circunscripto por los términos de la norma que la convoca y le atribuye competencia".

En apoyo de la decisión de declarar la "nulidad" de la reforma constitucional en este punto, se remite a dicha consecuencia, como prevista en la Ley $\mathrm{N}^{\circ} 24.309$, cuyo artículo $6^{\circ}$ dispuso que “...serán nulas de nulidad absoluta todas las modificaciones, derogaciones y agregados que realice la Convención Constituyente apartándose de la competencia establecida en los arts. $2^{\circ}$ y $3^{\circ}$ de la presente ley de declaración... ". El juez Vásquez concluye que la Corte se halla facultada "para cumplir con el mandato implícito contenido en tal precepto resolviendo lo propio. La misma presencia del artículo $6^{\circ}$ de la ley 24.309 presupone la existencia de un poder dotado de facultades suficientes para realizar el control de la competencia actuada por la convención reformadora, que permita privar de efectos aquello realizado en infracción a los límites impuestos, el cual no puede ser otro que aquel que tiene como atribución esencial la de preservar la supremacía constitucional: el Judicial". Lo que cabe preguntarse en relación con este argumento, es si son suficientes las competencias de la Corte, como intérprete último de la Constitución, para hacer tal declaración. Es decir, ¿puede bajo pretexto de la interpretación, anular un precepto constitucional? Por otra parte, el rol cautelar de la supremacía constitucional ¿se extiende a la reforma de la Constitución?

Sobre la materia, Raúl Gustavo Ferreyra ha señalado que en la Constitución argentina el poder constituyente reformador no es ilimitado “... no debe colegirse que la Convención pueda ser independiente de la ley mayor. La Convención es un poder instituido al que la Constitución atribuye su reformabilidad" 15 . Si entendemos la Constitución como una "unidad", significa que todas sus disposiciones refieren su producción a una misma regla de reconocimiento, que es la regla democrática. Esto puede predicarse, además, de la totalidad del sistema jurídico, cuya validez arranca de ella. La infracción de la regla democrática en el procedimiento de reforma constitucional podría acarrear la ruptura de la continuidad constitucional. ¿Podríamos decir que si no hay sanción para ello, la regla es ineficaz? Si concluyésemos aquello, le negaríamos el carácter normativo a la Constitución ${ }^{16}$. La extralimitación implicaría necesariamente consecuencias jurídicas, ya que la Constitución es una norma. Esta conclusión puede servir de sustento a la actuación de la Corte en el caso Fayt: la declaración de la nulidad, en lo pertinente, de la reforma constitucional de 1994. La cuestión se resuelve, entonces, en el acto de

15 Ferreyra, Raúl Gustavo. "Patología del Proceso de Reforma. Sobre la Inconstitucionalidad de una Enmienda en el Sistema Constitucional de la Argentina”, en FERrer MAC-GREGor, Eduardo y ZALDívar LELO DE LARREA, Arturo (coordinadores). La Ciencia del Derecho Procesal Constitucional. Estudios en homenaje a Héctor Fix-Zamudio en sus cincuenta años como investigador del Derecho. Procesos Constitucionales Orgánicos, México D.F., UNAM - Instituto Mexicano de Derecho Procesal Constitucional - Marcial Pons, 2008, t. VIII, p. 803.

16 FErREYrA, "Patología del Proceso de Reforma...", op.cit., p. 805. 
adjudicación, ya que, como señala Kelsen, la acción reformadora no puede considerarse nula $a b$ initio, sino únicamente "anulable", y las condiciones de anulabilidad proceden en situaciones especiales. Una de esas situaciones especiales es la existencia dentro del sistema jurídico de un órgano distinto del legislador, encargado de la revisión judicial ${ }^{17}$, en el caso argentino, la Corte Suprema de Justicia de la Nación.

Establecido el punto acerca del carácter limitado del poder constituyente reformador, es interesante preguntarse por el carácter de esos límites. Si dichos límites son formales, nos remitimos a condiciones orgánicas y procedimentales de validez. Aparentemente la infracción de dichas condiciones orgánicas y procedimentales son más fáciles de resolver. La transgresión a dichas reglas harían aparecer claramente sus consecuencias derivadas. "La elección de determinado sujeto (Congreso y Convención Constituyente) y por un determinado proceso (iniciación, deliberación y sanción) establece una cuestión que afecta la competencia, limitada, de la reforma de la Constitución" ${ }^{\text {"18 }}$. Así las cosas, distintas causales de invalidez de una reforma, referidas a vicios en el procedimiento, acarrearían la inconstitucionalidad de la reforma constitucional ${ }^{19}$.

Una de las cuestiones a tener en consideración en relación con el poder constituyente derivado es el del sujeto de la competencia o función (parlamento, pueblo, ratificación en referéndum, etc.). Otra, la de los alcances de los obstáculos procesales a las modificaciones constitucionales (quórums reforzados), o si existen disposiciones formales adicionales, por ejemplo, si hay mandato de modificación expresa del texto de la Constitución, para hacer visible, a priori, las intenciones del poder pre constituyente, u otros límites, por ejemplo el del tiempo (no se modificará sino en 5 años más, por ejemplo) ${ }^{20}$.

Ahora bien, en cuanto a los llamados límites materiales a la potestad constituyente derivada, la discusión es mucho más compleja, porque compromete establecer si existe o no una limitación jurídica del pueblo soberano, que pone en evidencia la pretensión de control sobre las opiniones de las generaciones futuras ${ }^{21}$. ¿Podría, so pretexto del ejercicio del poder reformador, transformarse la República en Monarquía, o el sistema federal en unitario, o desaparecer el catálogo de derechos humanos reconocidos? ${ }^{22}$

Ello agrega una arista de complejidad al caso en análisis, ya que nos podemos preguntar si efectivamente en el caso Fayt observamos una infracción a una mera regla de procedimiento (la Convención reforma la Carta Política en una materia no autorizada por el Congreso), o en

\footnotetext{
Kelsen, Hans. Teoría General del Derecho y del Estado. México D.F., Imprenta Universitaria,1949, p. 164.

FERreyra, "Patología del Proceso de Reforma...”, op.cit., p. 811.

9 Ferreyra, "Patología del Proceso de Reforma...", op.cit., p. 829.

HÄBERLE, El Estado Constitucional..., op.cit., p. 255.

Ferreyra, "Patología del Proceso de Reforma...”, op.cit., p. 814.

22 Por ejemplo, la Constitución alemana prohíbe cualquier reforma al régimen federal; la Constitución italiana declara intangible la forma republicana; la Constitución brasileña prohíbe la eliminación los derechos fundamentales. Por otro lado, ejemplos de Constituciones que prevén su reforma total, aunque con mecanismos de quórum reforzados y complejidades orgánicas y procedimentales son la Constitución argentina, la chilena, la boliviana, la ecuatoriana y la
} venezolana. 
Revista Tribuna Internacional

Volumen $4 \cdot \mathrm{N}^{\text {o } 8} \cdot 2015 \cdot$ pp. 255-269

ISSN 0719-482X (versión en línea)

realidad es una infracción a un elemento sustancial del sistema democrático, cual es la mantención de la independencia del Poder Judicial (al afectar en esencia el principio de inamovilidad de los magistrados, una de las garantías del debido proceso, derecho humano básico de los habitantes), elemento sustancial al Acuerdo Básico de 1853/60. En la sentencia se menciona como argumento de justificación externa que la relación existente entre la inamovilidad de los magistrados y los derechos humanos es lo que se defiende en el fallo, para que no se entienda que es una defensa corporativa a un privilegio estamental.

Peter Häberle señala que hay límites escritos y no escritos al poder constituyente del pueblo, como el que encontramos en la Constitución francesa de 1958, cuyo preámbulo mantiene la vigencia de la Declaración de los Derechos del Hombre y del Ciudadano: “Toda sociedad en la que la garantía de los derechos no esté asegurada, ni determinada la división de poderes, no tiene Constitución". El pueblo en el Estado Constitucional tiene límites al ejercicio del poder constituyente. El hecho que sea una auto obligación voluntaria, frente a un trasfondo de un "poder ilimitado por principio" es una errónea forma de concebir el poder constituyente, que requiere normalidad y normatividad de un principio constitucional inmanente al Estado Constitucional. Los derechos humanos, por ejemplo, son determinantes culturales, valores fundamentales objetivos ${ }^{23}$, y por ende, intangibles.

Häberle postula que debe distinguirse si estamos en un estado más abstracto, del tipo del estado constitucional, o bien si el proceso de reforma se refiere a un pueblo ya constituido. El pueblo en concreto, ya no tiene la potestad de modificar totalmente su forma de constitución. Por ejemplo, Estados Unidos y Suiza no pueden disponer de la modificación de la forma de Estado federal, que pasa a ser intangible porque se ha producido la "normativización y constitucionalización" del poder constituyente del pueblo. "En este estado cultural, ni la nación ni el pueblo se encuentran en estado de naturaleza o de excepción, en el sentido de las doctrinas que van de Sieyès hasta C. Schmitt" ${ }^{\prime 24}$.

En el estado constitucional, que tiene pretensiones normativas, o mejor dicho, logra su realización en la normatividad, tanto la revisión parcial o "modificación de la constitución" como la revisión total, o "proceso constituyente", deben estar regulados en el texto constitucional. Ambos deben entenderse -como proceso constituyente- dependientes del poder constituido, porque realizan la "normación de lo políticamente significativo", es decir, afirman las posibilidades de realización del proyecto político, en una forma normativa, o bien, como una específica normatividad en la dimensión del tiempo, en el pasado, presente y futuro de un pueblo, de modo que se expresen en el texto constitucional esperanzas hacia el futuro, posibilidades de conformarlo y criterios (objetivos), es decir, requisitos del deber ser típicoideales $^{25}$. Esta idea tiene bastante densidad normativa en la jurisprudencia del Tribunal

\footnotetext{
HÄBERLE, El Estado Constitucional..., op.cit.,p. 247.

HÄBERLE, El Estado Constitucional..., op.cit., p. 246.

HÄBERLE, El Estado Constitucional..., op.cit., p. 251.
} 
Constitucional Federal alemán, que ha caracterizado a los derechos fundamentales como un sistema objetivo de valores ${ }^{26}$.

Para Häberle, la Constitución debe establecer límites a la modificación de la Carta Magna, o "cláusulas de eternidad", que pueden resumirse en los principios de dignidad humana, derechos humanos, principio democrático, división de poderes, y el estado social de derecho ${ }^{27}$.

No obstante lo anterior, existe en este punto una diferencia radical entre los modelos constitucionales aludidos por Häberle, fundamentalmente la Constitución alemana y otros textos europeos, con el derecho constitucional argentino, que, a mi juicio, puede resolver la cuestión de los límites materiales al poder reformador, y es que la Constitución Federal argentina no establece un núcleo jurídicamente intangible, lo que es coherente con la posibilidad prevista en la Carta Fundamental de su reforma total. La Constitución no establece límites materiales expresos al poder constituyente ${ }^{28}$.

\subsection{Límites a la justiciabilidad de la enmienda}

La Corte estimó que podía avocarse la revisión de la enmienda constitucional. Sobre el particular señaló: "El Poder Judicial está habilitado para juzgar, en los casos que se le planteen, si el acto impugnado ha sido expedido por el órgano competente, dentro del marco de sus atribuciones y con arreglo a las formalidades a que está sujeto".

De este modo, la Corte resolvió que no era una cuestión política no justiciable, cuestión polémica en todo ordenamiento constitucional, ya que se ha planteado que la retracción del control judicial de las cuestiones políticas es atentatoria del derecho a la jurisdicción de la parte afectada, una renuncia del Estado al ejercicio de la jurisdicción, que impide el remedio constitucional y esfumándose la responsabilidad del Estado ${ }^{29}$.

Hemos establecido el carácter limitado que tiene el poder constituyente derivado, distinguiendo entre límites formales y límites materiales. Como señala Ferreyra, "los poderes conferidos a las Convenciones Constituyentes no pueden reputarse ilimitados (algo bastante sabido) porque el ámbito de aquellos se halla circunscripto por la disposición normativa que la convoca y le atribuye competencia" 30 . Hemos concluido que los límites materiales al poder constituyente reformador no son un problema en el derecho constitucional argentino, por cuanto la Constitución no establece cláusulas pétreas ni un núcleo intangible, como sí lo hacen otros sistemas constitucionales. Habiendo establecido que existen límites formales al poder

\footnotetext{
BVerfGE 40 (Tribunal Constitucional Federal alemán, 40, 248); GG (Ley Fundamental art. 20 III).

HÄBERLE, El Estado Constitucional..., op.cit., p. 260.

Ferreyra, "Patología del Proceso de Reforma...”, op.cit., p. 815.

Bidart CAmpos, Germán. Compendio de Derecho Constitucional. $1^{a}$ reimpresión de la $1^{\text {a }}$ edición. Buenos Aires, EDIAR, 2008, pp. 404-405.

30 Ferreyra, Reforma Constitucional..., op.cit., p. 203.
} 
Revista Tribuna Internacional

Volumen $4 \cdot \mathrm{N}^{\text {o }} 8 \cdot 2015 \cdot$ pp. $255-269$

ISSN 0719-482X (versión en línea)

constituyente reformador, la consecuencia lógica es preguntarse qué ocurre cuando el órgano extralimita los contornos de su competencia en este ámbito de atribuciones. Aquélla sería la inconstitucionalidad de la reforma.

Lo que cabe preguntarse ahora es ¿qué órgano está habilitado para declarar la inconstitucionalidad de la reforma? y ¿qué límites tiene dicho órgano para formular la declaración de inconstitucionalidad?

Siguiendo la doctrina Marshall, Jorge Amaya señala que es el poder judicial el que debe ejercer el control de la constitucionalidad, como afirmación del principio democrático equilibrado con la protección de los derechos fundamentales. La acción de una Convención Constituyente no tendría por qué escapar de este control. Sobre el particular el autor plantea que "la capacidad de declarar la validez o invalidez de las normas que integran un sistema jurídico por ser contrarias a la norma básica o de referencia (Constitución) deposita en el Poder Judicial un carácter 'contra mayoritario' de control y equilibrio de dicho proceso democrático, a través de su misión de inclinarse por el fortalecimiento de los derechos y principios constitucionales" ${ }^{\text {"31. }}$.

El fallo en análisis es tan importante porque es la primera vez que la Corte Suprema argentina actúa con total claridad en orden a establecer que es el órgano competente para declarar la inconstitucionalidad de la enmienda constitucional. El precedente de Fayt implica el reconocimiento de los efectos de la extralimitación de la Convención Constituyente: su nulidad o inconstitucionalidad; como asimismo, el reconocimiento de la competencia de la Corte Suprema para conocer judicialmente de la impugnación a la reforma constitucional.

El tratamiento que la Corte da al problema de la inconstitucionalidad de la reforma, es el mismo que adjudica al actuar inconstitucional de cualquier rama del gobierno constituido. Equivale a declarar la inconstitucionalidad del actuar del Ejecutivo, en el ámbito del derecho administrativo, o del Legislativo en el ámbito de la creación de la ley. El problema a determinar, entonces, es si una Convención Constituyente equivale a una rama del gobierno constituido, ¿es un poder constituido por la Constitución o dicho poder configura a la Constitución? $?^{32}$.

La tesis con arreglo a la cual el procedimiento de reforma constitucional no sería revisable por ser una cuestión política no sujeta a la jurisdicción, cede en este caso frente a las argumentaciones de la Corte, basadas en el principio de supremacía constitucional, que entiende a la Convención como una rama más del gobierno constituido, y como tal, susceptible de control y cuyo trabajo puede estar sometido a examen de constitucionalidad, no obstante haberse dado origen ya a una nueva Carta Magna. La irrevisibilidad del procedimiento de reforma constitucional presupone la actuación del Congreso dentro de los límites

\footnotetext{
31 AmayA, Jorge Alejandro. "Ideologías Políticas e Ideologías Judiciales: Reflexiones sobre la doctrina de la Corte Suprema Argentina en torno a los delitos de lesa humanidad (Estamos muy tranquilos allí [en la Corte Suprema], pero es la calma del centro de una tormenta, como todos sabemos)", en Revista de Estudios Jurídicos, No 8. Universidad de Jaén, 2008, p. 7.

32 FERrEYra, Reforma Constitucional..., op.cit., p. 219.
} 
constitucionales $^{33} \cdot \sum^{L}$ Los jueces pensaban seriamente que una convención constituyente es una rama del gobierno constituido? $?^{34}$

Nos haremos algunas preguntas que se refieren a los límites a la justiciabilidad de la enmienda constitucional.

1.- ¿Puede la Corte introducir una enmienda constitucional bajo pretexto del control de constitucionalidad de la reforma a la Constitución realizado por la Convención Nacional Constituyente?

El argumento es que la Convención excede su ámbito de competencias, al no estar la inamovilidad de los magistrados puesta en la ley que declara la necesidad de reforma y fija los puntos de ella. So pretexto de ser legislador negativo, en este caso se transforma en constituyente positivo, al reformar la Constitución, reponiendo en los hechos la normativa constitucional anterior, ya enmendada por la Convención Nacional Constituyente. "La sentencia pronunciada en 'Fayt', con envase de 'interpretación' contiene una enmienda constitucional. En rigor, su contenido constituye una invención jurídica, que desagrega -¿para este caso? - un texto explícito incluido democráticamente por el poder reformador" ${ }^{35}$. Este, a mi juicio, es el problema más serio del árbol de cuestiones que abre la judiciabilidad de la reforma constitucional. En los hechos la Corte está enmendando la Constitución, ¿tiene atribuciones para hacer aquello?

2.- ¿Pueden los jueces expulsar normas constitucionales del sistema jurídico si el juicio de constitucionalidad es concreto y no abstracto?

Sobre este punto, la Corte Suprema no se cuestiona los alcances que tendrá la sentencia. El efecto de las sentencias en Argentina es relativo, vale decir, sólo afecta a las partes del juicio, por tanto el efecto erga omnes no depende de la declaración de inconstitucionalidad, sino de la declaración de nulidad de la reforma en lo relativo a la inamovilidad de los jueces. En efecto, al declarar la inconstitucionalidad sólo podría establecerse efectos para las partes, Fayt y el Estado. Pero la declaración de nulidad, de suyo, debe aplicarse respecto de todos, aunque es un tema no resuelto.

3.- ¿Alcanzan las competencias de control de constitucionalidad de la Corte, respecto de los poderes públicos, el trabajo de la Convención Nacional Constituyente?

Para la Corte no hay dudas en esto, ya que considera a la Convención como un órgano más del Estado, susceptible de control. La obra de la Convención, por ende, puede ser puesta en tela de juicio, si el procedimiento que regula el poder reformador no se ha cumplido. No tiene la Convención aptitud para mantenerse inerme al examen de constitucionalidad de su actuar. La

\footnotetext{
FERreyra, Reforma Constitucional..., op.cit., p. 208.

4 Ferreyra, Reforma Constitucional..., op.cit., p. 219.

5 FERreyra, Reforma Constitucional..., op.cit., p. 223.
} 
Revista Tribuna Internacional

Volumen $4 \cdot \mathrm{N}^{\text {o }} 8 \cdot 2015 \cdot$ pp. $255-269$

ISSN 0719-482X (versión en línea)

Corte le desconoce de algún modo, por ende, el carácter constituyente. La Convención es configurada por la Constitución; no configura ella a la Constitución.

El argumento con arreglo al que los magistrados del Máximo Tribunal no podrían pronunciarse sobre la constitucionalidad de la enmienda a la Carta Política, ya que juraron cumplir y hacer cumplir la Constitución, con sus reformas, incluida la de 1994 (en los términos de las normas que condicionaron el funcionamiento de la Convención Nacional Constituyente), es desechado enérgicamente por el juez Vásquez, quien señala que precisamente en honor a dicho juramento es que la Corte debe pronunciarse sobre la nulidad de cláusulas que la contraríen.

Marcelo López Alfonsín y Ariela Schnitman, sostienen la inconveniencia de la justiciabilidad de la reforma constitucional, no obstante precisar que la inconveniencia se refiere al órgano habilitado en el sistema de control difuso: los tribunales de justicia. "¿No sería mejor que el Poder Judicial fallara en asuntos pura y exclusivamente jurídicos? Debemos aclarar que no se propone aquí la ampliación de la esfera de las ya mencionadas 'cuestiones políticas no justiciables' sino todo lo contrario: proveer una solución distinta para aquellos casos donde la actividad jurisdiccional ingresa en el terreno político, quitándosela al Poder Judicial para entregársela a otro órgano de competencia exclusiva para asuntos constitucionales; pero todo ello sin dejar de sostener que todas las cuestiones atinentes a la Constitución deben ser justiciables, sino que algunas deben ser ventiladas ante otro órgano, más especializado para juzgarlas." ${ }^{36}$

El fallo del juez Bossert, indirectamente y sin declararlo explícitamente, pretende salvar la reforma constitucional, evitando la declaración de nulidad (¿no inconstitucionalidad?) de la enmienda en lo relativo al artículo $99 \mathrm{~N}^{\circ} 4$ de la Constitución. ¿Habrá tenido en consideración estos argumentos limitativos a la acción de los tribunales, frente al trabajo de la Convención, que está configurando el derecho constitucional futuro? Señala el voto separado de Bossert que, al tener más de 75 años el juez Fayt, no se le puede aplicar la restricción introducida por la reforma, ya que la misma no alcanza a las personas que con anterioridad a la entrada en vigencia de la misma, 22 de agosto de 1994, hayan ya cumplido los 75 años. De esta manera, confirma la sentencia de la Cámara de Apelaciones de lo Contencioso Administrativo, en cuanto acoge la acción declarativa del magistrado, tendiente a evitar que se le aplique a él la referida enmienda, pero sin alterar el texto constitucional reformado.

36 López Alfonsín, Marcelo y Schnitman, Ariela. "Salvataje a la Reforma". Trabajo preparado para su presentación en el $\mathrm{X}$ Congreso Nacional y III Congreso Internacional sobre Democracia, sobre "El Control de Constitucionalidad en Argentina", organizado por la Facultad de Ciencia Política y Relaciones Internacionales de la Universidad Nacional de Rosario. Rosario, 3 al 6 de septiembre de 2012, pp. 19-20. 
La justiciabilidad de la reforma constitucional en la República Argentina. El caso Fayt Alvaro Fuentealba Hernández

\subsection{Líneas doctrinarias presentes en el caso}

1.- Mientras el poder constituyente originario es ilimitado y extrajurídico, ya que salvas excepciones $^{37}$ no emana del poder constituido, el poder constituyente derivado es esencialmente limitado, tanto por contornos formales (procedimentales y orgánicos), como por determinantes materiales (derechos humanos, dignidad, estado social de derecho, régimen democrático, cláusulas federales) cuando los textos constitucionales así lo establecen, o bien, cuando establecen núcleos de intangibilidad.

2.- El poder constituyente derivado, en la Constitución argentina, sólo tiene límites formales. Está limitado no sólo por la Constitución, sino por la ley que declara la necesidad de la reforma. El pueblo establece, además, dicho límite, al momento de elegir a los convencionales.

3.- La modificación del régimen de inamovilidad de los jueces es nula por cuanto excede los límites que estableció la ley que declaró la necesidad de la reforma. La Convención Nacional Constituyente excedió los límites normativos que determinaban las posibilidades de realización del poder constituyente derivado.

4.- No era materia de la Convención Nacional Constituyente la designación de los magistrados federales.

5.- Es procedente la declaración de nulidad de la reforma constitucional en esta parte, aplicando la consecuencia jurídica explicitada en la Ley $\mathrm{N}^{\circ} 24.309$.

6.- La reforma constitucional no es una cuestión política no justiciable. Al ser justiciable, la Corte Suprema posee atribuciones para conocer de ella.

\section{A modo de conclusión: Nuestra opinión}

En una primera lectura, el caso Fayt aparenta no poner de relieve un tema problemático. En efecto, se trata del juicio de la actuación de una autoridad, su marco de atribuciones para ello, la eventual afectación de un derecho y la comparación de la referida actuación con los estándares constitucionales establecidos.

Mas, cuando nos preguntamos de qué categoría de autoridad estamos juzgando, y aparece que es la Convención Nacional Constituyente, máxima expresión del poder creador de derecho, debemos necesariamente responder preguntas muy relevantes.

37 La Constitución de Venezuela establece que una vez convocada la Asamblea Constituyente, ésta ejerce el poder constituyente originario. Regulación análoga del poder constituyente originario, emanado del poder constituido, encontramos en la Constitución del Ecuador y en la Constitución de Bolivia. 
Revista Tribuna Internacional

Volumen $4 \cdot \mathrm{N}^{\mathrm{o}} 8 \cdot 2015 \cdot$ pp. $255-269$

ISSN 0719-482X (versión en línea)

1. ¿Está limitado el poder constituyente?

2. ¿De qué clase son esos límites?

3. ¿Existe un órgano autorizado a velar por el cumplimiento de la acción del constituyente dentro de dichos límites?

4. ¿Qué consecuencias se pueden acarrear de dicha constatación?

Hemos establecido que los límites al poder constituyente derivado no hacen sino reafirmar el carácter normativo de la propia Constitución.

La pregunta acerca del tipo de límites que pueden operar en la esfera del control de constitucionalidad de la reforma, la hemos respondido estableciendo que, en el derecho constitucional argentino, sólo pueden ser límites formales, referidos a procedimiento, órgano y reglas de competencia.

El problema de la justicia constitucional es de suyo interesante. ¿Puede un poder contra mayoritario, como el Poder Judicial, expulsar del ordenamiento jurídico un texto autoritativo normativo democráticamente generado, como la ley?

En general, quienes defienden la justicia constitucional sostienen que no hay problemas en aquello, ya que de lo que se trata es de algo simple: declarar la inadecuación de la ley con la Carta Política. Pero ¿se aplica el mismo criterio cuando lo que expulsamos del ordenamiento jurídico es una norma constitucional? ¿Puede haber reforma constitucional inconstitucional? Y ¿no está en ese caso la Corte creando normas constitucionales al hacer supervivir el texto anterior reformado?

Por último, en relación con las consecuencias, la declaración de inconstitucionalidad de la reforma hace supervivir el texto original. Estando aquello claro, procede preguntarnos acerca del efecto de la declaración: ¿Opera erga omnes o mantiene los efectos relativos de toda sentencia?

La sentencia de caso Fayt determinó que el poder constituyente es limitado, que dichos límites son formales, que la infracción a dichos límites puede ser conocida por la Corte Suprema, y que la sanción a dicha extralimitación es la nulidad de la enmienda, que estaba prevista en la ley que declaró la necesidad de reforma.

Así las cosas, podemos concluir que el poder constituyente reformador tiene el mismo estatus que cualquier otra autoridad creadora de derecho y debe someterse, en consecuencia, al principio de supremacía constitucional.

Si aceptamos estos elementos de análisis, no podemos concluir que la Corte esté excediendo sus atribuciones, máxime si en la tradición de la judicial review se entiende que en esencia, es el tribunal quien debe velar por el principio de juridicidad, el que alcanza a toda fuente creadora de derecho en un Estado constituido, incluso aquel poder llamado a reformar la norma máxima del ordenamiento jurídico, cuando dicho poder tiene expresos límites establecidos en la misma. 